\title{
Role of SDHAF2 and SDHD in von Hippel- Lindau Associated Pheochromocytomas
}

\author{
Johan Kugelberg, Jenny Welander, Francesca Schiavi, Ambrogio Fassina, Martin Backdahl, \\ Catharina Larsson, Giuseppe Opocher, Peter Söderkvist, Patricia L. Dahia, Hartmut P. H. \\ Neumann and Oliver Gimm
}

\section{Linköping University Post Print}

\section{Tweet}

N.B.: When citing this work, cite the original article.

The original publication is available at www.springerlink.com:

Johan Kugelberg, Jenny Welander, Francesca Schiavi, Ambrogio Fassina, Martin Backdahl, Catharina Larsson, Giuseppe Opocher, Peter Söderkvist, Patricia L. Dahia, Hartmut P. H. Neumann and Oliver Gimm, Role of SDHAF2 and SDHD in von Hippel-Lindau Associated Pheochromocytomas, 2014, World Journal of Surgery, (38), 3, 724-732.

http://dx.doi.org/10.1007/s00268-013-2373-2

Copyright: Springer Verlag (Germany) http://www.springerlink.com/?MUD=MP

Postprint available at: Linköping University Electronic Press

http://urn.kb.se/resolve?urn=urn:nbn:se:liu:diva-106102 


\section{Role of $S D H A F 2$ and $S D H D$ in von Hippel-Lindau associated pheochromocytomas}

Johan Kugelberg ${ }^{1, \#}$, Jenny Welander ${ }^{1, \#}$, Francesca Schiavi ${ }^{2}$, Ambrogio Fassina ${ }^{3}$, Martin Bäckdahl ${ }^{4}$, Catharina Larsson ${ }^{5}$, Giuseppe Opocher ${ }^{2,6}$, Peter Söderkvist ${ }^{1}$, Patricia L. Dahia ${ }^{7}$, Hartmut P.H. Neumann ${ }^{8}$, and Oliver Gimm ${ }^{9}$ **

${ }^{1}$ Department of Clinical and Experimental Medicine, Faculty of Health Sciences, Linköping University, Linköping, Sweden, ${ }^{2}$ Familial Cancer Clinic, Veneto Institute of Oncology IRCCS and ${ }^{3}$ Department of Medicine (DIMED), Surgical Pathology \& Cytopathology Unit, University of Padua, Padua, Italy, ${ }^{4}$ Department of Molecular Medicine and Surgery, Karolinska Institutet, Stockholm, Sweden, ${ }^{5}$ Department of Oncology-Pathology, Karolinska Institutet, CCK, Stockholm, Sweden, ${ }^{6}$ Department of Medicine (DIMED), University of Padua, Padua, Italy, ${ }^{7}$ Department of Medicine, Cancer Therapy and Research Center, University of Texas Health Science Center, San Antonio, USA, ${ }^{8}$ Department of Nephrology, Section of Preventive Medicine, Albert-Ludwigs-University of Freiburg, Germany, ${ }^{9}$ Department of Clinical and Experimental Medicine, Faculty of Health Sciences, Linköping University, Department of Surgery, County Council of Östergötland, Linköping, Sweden

Abbreviated title: $S D H A F 2$ and $S D H D$ in VHL-associated pheochromocytomas

Keywords: $S D H A F 2, S D H 5, S D H D$, von Hippel-Lindau, VHL, pheochromocytoma, adrenal paraganglioma, $\mathrm{LOH}$, mutation, promoter methylation, gene expression

\section{\#These authors contributed equally}

\section{*Corresponding author:}

Oliver Gimm, MD

Department of Clinical and Experimental Medicine \& Department of Surgery

Linköping University

58185 Linköping

Sweden

E-mail: oliver.gimm@liu.se

Phone: +46-10-1033022

Fax: +46-10-1033570 


\begin{abstract}
Pheochromocytomas (PCCs) develop from the adrenal medulla and are often part of a hereditary syndrome such as von Hippel Lindau (VHL) syndrome. In VHL, only about $30 \%$ of patients with a VHL missense mutation develop PCCs. Thus, additional genetic events leading to formation of such tumors in patients with VHL syndrome are sought for. SDHAF2 (previously termed SDH5) and SDHD are both located on chromosome 11q and required for the function of mitochondrial complex II. While SDHAF2 has been shown to be mutated in patients with paragangliomas (PGLs), SDHD mutations have been found in both patients with PCCs and PGLs. Since loss of 11q is a common event in VHLassociated PCCs, we aimed to investigate whether SDHAF2 and SDHD are targets. In this study, 41 VHL-associated PCCs were screened for mutations and loss of heterozygosity (LOH) in SDHAF2 or $S D H D$. Promoter methylation as well as mRNA expression of $S D H A F 2$ and $S D H D$ was studied. In addition, immunohistochemistry (IHC) of $S D H B$, known to be a universal marker for loss of any part the SDH complex, was conducted. LOH was found in more than $50 \%$ of the VHL-associated PCCs, and was correlated to a significant decrease $(\mathrm{p}<0.05)$ in both $S D H A F 2$ and $S D H D$ mRNA expression, which may be suggestive of a pathogenic role. However, while SDHB protein expression as determined by IHC in a small cohort of tumors was lower in PCCs than in the surrounding adrenal cortex, there was no obvious correlation with LOH or the level of SDHAF2/SDHD mRNA expression. In addition, the lack of mutations and promoter methylation in the investigated samples indicate that other events on chromosome 11 might be involved in the development of PCCs in association with VHL syndrome.
\end{abstract}




\section{Introduction}

Pheochromocytomas (PCCs), also termed adrenal paragangliomas (PGLs), are tumors derived from chromaffin cells in the adrenal medulla while PGLs develop from neural crest-derived paraganglia of the autonomic nervous system and can be found throughout the body from the pelvis to the head and neck [1]. They frequently cause hypertension due to excessive catecholamine production and secretion. With the current data related to discoveries of new genes in the pathogenesis of PCCs and PGLs, the proportion of hereditary tumors is estimated to be around 30-35\% [2-4]. The vast majority of these patients belong to one of the following syndromes: von Hippel-Lindau (VHL) [5], multiple endocrine neoplasia type 2 (MEN 2) [6], von Recklinghausen (NF1) [7] or pheochromocytomaparaganglioma syndrome (PGL types 1-4) [8-11], which are caused by germline mutations in $V H L$, RET, NF1 and SDHx (SDHA, SDHB, SDHC, SDHD, and SDHAF2/SDH5), respectively. In addition, germline mutations in KIFIB $\beta$ have been found in patients with PCCs, neuroblastomas and other neural and non-neural tumors $[12,13]$. More recently, EPASI/HIF2A germline mutations were found in patients with PCCs/PGLs and polycythemia (polycythemia-paraganglioma syndrome) [14] Susceptibility genes for which no syndromic form has been described yet include EGLN1 [15], TMEM127 [16] and MAX [17].

The majority of patients with VHL-associated PCCs have missense VHL germline mutations [18]. While probably less than $1 \%$ of patients with nonsense, microdeletion/insertion, or deletion germline mutations of VHL develop PCCs, about $30 \%$ of patients with missense germline mutations do so. Since only a subset of patients with missense VHL germline mutations develop PCCs, additional genetic events contributing to the formation of such tumors are sought after. Loss involving the long arm of chromosome 11 (11q) has been reported in almost 70\% of VHL-associated PCCs [19] but no specific additional PCC triggering gene has yet been identified.

The SDH complex (mitochondrial complex II) plays an important role in the electron transport chain and the Krebs cycle [20]. SDHAF2 (succinate dehydrogenase complex assembly factor 2), a gene located on chromosome 11q12.2, encodes a protein that interacts with the catalytic subunit of the SDH complex and is required for SDH-dependent respiration. SDHAF2 was shown to act as a tumor 
suppressor [21], and mutations in the gene were detected in unrelated families with hereditary PGLs [21, 22]. SDHD (succinate dehydrogenase complex, subunit D, integral membrane protein) is located on chromosomal region 11q23. The gene encodes a protein forming one of two transmembrane subunits in the SDH complex, important for the function of the electron transport chain [20].

This study investigates whether SDHAF2 and/or SDHD are targets of additional altering events within 11q that could promote PCC development in carriers of $V H L$ germline mutation. A panel of VHLassociated PCCs was screened for mutations and loss of heterozygosity (LOH) in SDHAF2 and SDHD. Promoter methylation was investigated as an alternative mechanism of gene inactivation, and levels of mRNA expression of SDHAF2 and SDHD were analyzed in tumors with and without $\mathrm{LOH}$. Finally, protein expression studies were conducted by staining for the SDHB protein since it is considered a universal marker for loss of any of the SDH subunits [23].

\section{Materials and Methods}

\section{Patients and samples}

Forty-one PCCs from 40 patients with a VHL missense germline mutation were studied. For 19 of these tumors paired blood samples were available for LOH analysis. The samples were obtained through the University of Freiburg, Germany, the University of Padova, Italy, and the University of Texas Health Science Center, USA. Tumor and blood samples were snap frozen in liquid nitrogen and stored at $\leq-70^{\circ} \mathrm{C}$, or in some cases stored in RNAlater (Ambion, Austin, TX). DNA was isolated using TRIzol (Invitrogen, Paisley, UK) or previously published methods [19], and RNA was isolated using TRIzol (Invitrogen). Informed consent was given in all cases and the local ethic committees approved the study.

\section{LOH analysis by microsatellite genotyping}

Tumor and blood samples were genotyped for microsatellite markers D11S4191, D11S1765, D11S4076 and D11S1883 which are all in close proximity to SDHAF2, as well as D11S1793, D11S1986, D11S897, D11S3179 in close proximity to SDHD (Table 1). 
For each marker, 50 ng of DNA was amplified for 35 cycles using HotStar Taq Polymerase (Qiagen, Hilden, Germany) with primers and annealing temperatures as specified in Table 1. Forward primers were labeled with 6-FAM fluorophore (Sigma-Aldrich, St. Louis, MO). Amplicons were denatured at $95{ }^{\circ} \mathrm{C}$ and separated by capillary electrophoresis on a 3500 Genetic Analyzer (Applied Biosystems, Foster City, CA). 600-LIZ (Applied Biosystems) was used as a size standard and results were analyzed with GeneMapper v. 4.0 (Applied Biosystems). Tumors were regarded as positive for LOH when the mean allele ratio between tumor and blood, calculated as earlier described [24], was $<0.7$ for all informative markers and apparent differences between tumor and blood allele ratios were seen in the electropherograms. In cases where no blood was available, allele peak ratios were compared to blood samples with the same or very similar allele combinations, followed by careful visual inspection of the electropherograms. Obvious allelic imbalance, i.e. large differences in allele peak heights and/or a higher peak in the longest allele were regarded as indicative of loss. Cases inconclusive at visual inspection and/or with one or more allele ratios $>0.7$ but $<0.8$ were regarded as inconclusive for $\mathrm{LOH}$.

\section{DNA sequencing}

$S D H A F 2$ and $S D H D$ both contain 4 exons and 3 introns. Primers were designed to amplify exons 1-4, for each gene, including the 5'- and 3'-untranslated regions (Table 2). For each exon, 50 ng of tumor DNA was PCR-amplified for 35 cycles using Thermo White Taq DNA Polymerase (Saveen Werner, Limhamn, Sweden) at annealing temperatures as specified in Table 2. PCR products were purified from unconsumed primers and dNTPs with ExoSAP-IT (GE Healthcare, Waukesha, WI) and Sanger sequencing was performed by a dideoxynucleotide chain termination reaction using BigDye Terminator 1.1 (Applied Biosystems) and the above primers. Separation was performed by capillary electrophoresis on a 3500 Genetic Analyzer (Applied Biosystems). Sequences were analyzed by alignment to the Ensembl sequence in NCBI BLAST as well as by visual inspection in Sequence Scanner v 1.0 (Applied Biosystems).

\section{Methylation specific PCR}


Promoter methylation was studied by methylation-specific PCR [25], using primers specific for the unmethylated (U) and methylated (M) sequence. in the SDHAF2 and SDHD gene promoters using previously described methodology [26]. Bisulfate conversion of $400 \mathrm{ng}$ of tumor DNA was performed using the EZ DNA Methylation Kit (Zymo Research, Irvine, CA). One $\mu$ l of product was used in each PCR (U and M), using HotStar Taq Polymerase (Qiagen, Hilden, Germany) with the following conditions: $95^{\circ} \mathrm{C}$ for $15 \mathrm{~min}, 38$ cycles of $\left(94^{\circ} \mathrm{C}\right.$ for $40 \mathrm{~s}, 58^{\circ} \mathrm{C}$ for $40 \mathrm{~s}, 72^{\circ} \mathrm{C}$ for $\left.40 \mathrm{~s}\right), 72^{\circ} \mathrm{C}$ for $5 \mathrm{~min}$ and hold at $4{ }^{\circ} \mathrm{C}$. PCR products were separated in $1.5 \%$ agarose gels containing ethidium bromide, and visualized with UV light. Methylated, unmethylated and non-converted wild-type DNA from the EpitTect PCR Control DNA Set (Qiagen) was used as controls. Bisulfite-converted blood-DNA samples from four patients were also included as controls.

The gene $\mathrm{HICl}$ (hypermethylated in cancer 1), which has previously been shown to be hypermethylated in VHL-associated PCCs [27], was analyzed as a control, using methylation-specific PCR with previously published primers [28].

\section{Quantitative mRNA expression analysis}

Expressions of $S D H A F 2$ and $S D H D$ mRNA were investigated using reverse transcription quantitative real time PCR (RT-qPCR) in those tumors for which RNA was available. RNA integrity was validated by microfluidic analysis on a 2100 Bioanalyzer (Agilent Technologies, Santa Clara, CA). $500 \mathrm{ng}$ of total RNA was transcribed into cDNA with Maxima First Strand cDNA Synthesis kit (Thermo Scientific, Waltham, MA). Gene expression was measured on the 7900HT Fast Real-Time PCR System (Applied Biosystems), using pre-designed primer-probe mixes covering exon boundaries [26] and the TaqMan® Fast Universal PCR Master mix (Applied Biosystems). GUSB and HPRTI (Applied Biosystems) were used as reference genes and were analyzed simultaneously with SDHAF2 and SDHD for all samples. These reference genes were selected since they have been shown stable expression in several tumor forms [29] and had expression levels comparable to SDHAF2 and SDHD in our samples. cDNA transcribed from 20 ng of total RNA was used in each reaction, and all reactions were performed in triplicates. Normalized relative expressions of $S D H A F 2$ and $S D H D$ were 
calculated according to established methods [30] as follows: mean threshold cycle $\left(\mathrm{C}_{\mathrm{T}}\right)$ value was calculated for each sample and gene by taking the mean of the PCR replicates. A normalized value $\left(\Delta \mathrm{C}_{\mathrm{T}}\right)$ was calculated by subtracting the mean of $\mathrm{C}_{\mathrm{T}(\mathrm{GUSB})}$ and $\mathrm{C}_{\mathrm{T} \text { (HPRT1) }}$ from $\mathrm{C}_{\mathrm{T} \text { (SDHAF2), and finally }}$ the relative expression was obtained as $2^{-\Delta \mathrm{CT}}$.

\section{Immunohistochemistry}

Immunohistochemistry was performed on 4-5 $\mu \mathrm{m}$ thick formalin-fixed and paraffin-embedded sections from each tumor sample in an automated system (Bond ${ }^{\mathrm{TM}} \_$maX, Menarini, Florence, Italy) according to the recommendations of the manufacturer. Anti-SDHB (mouse monoclonal, clone 21A11, Abcam, Cambridge, UK, dilution 1:1200, EDTA $30 \mathrm{~min}$ ) was used as primary antibody. Sections were then lightly counterstained with hematoxylin. Appropriate positive and negative controls were analyzed in parallel. The relative staining intensity was graded,,-+++ and +++ comparing adrenal medulla with adrenal cortex.

\section{Results}

\section{Frequent LOH at SDHAF2 and SDHD}

From 41 investigated VHL-associated PCCs, LOH or allelic imbalance indicative of LOH were identified in $22(54 \%)$ and $21(51 \%)$ tumors for SDHAF2 (Fig. 1a+1b) and SDHD, respectively (Fig. 1c+1d). Concerning SDHAF2, another 3 tumors (7\%) showed signs of LOH but this could not be fully determined (one or more allele ratios $>0.7$ but $<0.8$ and/or inconclusive at visual inspection). Regarding SDHD, this applied to 8 (20\%) tumors. Normal heterozygosity with no signs of LOH (allele ratios between 0.9 and 1.0 and/or no signs of loss in electropherograms) for SDHAF2 was found in 16 (39\%) tumors. Concerning SDHD, 12 (29\%) tumors showed normal heterozygosity.

\section{Screening for SDHAF2A and SDHD mutations}

No $S D H A F 2$ or $S D H D$ mutations were identified by direct sequencing in 39 informative PCCs. A common polymorphism (rs17702, C $\rightarrow$ T) in the 3'UTR region of exon 4 was detected in heterozygous 
form in 6 tumors (15\%) and, where available, the corresponding blood samples displayed the same genotype as the tumors. In tumors with $\mathrm{LOH}$, the peak size of one of the alleles was clearly reduced and sometimes hardly distinguishable. Allele frequencies of rs17702 did not differ significantly between the patients and 113 HapMap-CEU individuals reported at Ensembl ( $\mathrm{p}=0.12$, two-tailed Fisher's exact test).

\section{Promoter methylation analyses}

Methylation specific PCR for SDHAF2 and SDHD investigated in 27 PCC samples showed no promoter methylation. All samples yielded PCR products when using primers specific for unmethylated DNA but not when using methylation-specific primers (Fig. 2). In order to study the methylation status of our samples, the gene $\mathrm{HICl}$ was used as a control in methylation-specific PCR. HICl was found to be methylated in all tumor samples (Fig. 2) but not in any of the tested blood samples.

\section{Reduced SDHAF2 and SDHD expression}

The mean relative $S D H A F 2$ mRNA expression $\left(2^{-\triangle \mathrm{CT}}\right)$, normalized against the reference genes $G U S B$ and HPRT1, was 2.2 times lower in tumors with $\mathrm{LOH} /$ allelic imbalance compared to tumors with normal heterozygosity $(0.34 \pm 0.09$ and $0.74 \pm 0.31$, respectively). For $S D H D$, the mean relative expression was 2.9 times lower tumors with $\mathrm{LOH} /$ allelic imbalance than those without $(0.29 \pm 0.05$ and $0.78 \pm 0.24$, respectively). Differences in means were significant for both genes, $\mathrm{p}=0.0052$ for $S D H A F 2$ and $\mathrm{p}=0.042$ for $S D H D$, using two-tailed Student's t-test (Fig. 3).

\section{Immunohistochemistry}

SDHB protein expression intensity determined by immunohistochemistry was lower in the 6 analyzed PCCs (adrenal medulla) than in corresponding adrenal cortex (Fig. $4 \mathrm{a}+\mathrm{b}$ ). However, no obvious correlation was observed between the perceived staining intensity and $\mathrm{LOH}$ and/or levels of mRNA expression. 


\section{Discussion}

In this study, we show that loss of SDHAF2 and SDHD are frequent events in VHL-associated PCCs. More than $50 \%$ of our tumor samples clearly displayed LOH at the SDHAF2 and SDHD regions. Another $7 \%$ and $20 \%$ of the PCCs showed signs of $\mathrm{LOH} /$ allelic imbalance at the SDHAF2 and SDHD regions, respectively, but were inconclusive since the allele ratios were $>0.7$ but $<0.8$. A possible explanation for this could be a heterogeneity of the tumors, which has recently been shown in PCCs [31]. For both $S D H A F 2$ and $S D H D, \mathrm{LOH}$ was associated with a significantly $(\mathrm{p}<0.01$ and $\mathrm{p}<0.05$, respectively) decreased levels of mRNA expression.

Somatic mutations of SDHAF2 or SDHD were not detected in the investigated VHL-associated PCCs. Concerning $S D H A F 2$, this is in agreement with earlier studies since $S D H A F 2$ germline mutations have so far only been found in patients with PGLs but not in PCCss $[22,32]$. In contrast, mutations in $S D H D$ [33], SDHB [34], SDHC [35], and SDHA [36] were initially found in PGLs but later also in PCCs (SDHD [37, 38], SDHB [34], SDHC [11], SDHA [39]).

Promoter methylation of $S D H A F 2$ or $S D H D$ was not found in any of the investigated tumors. We did, however, detect promoter methylation of $\mathrm{HICl}$ a gene that has previously been found to be hypermethylated in VHL-associated PCCs [27] in all our investigated tumors (but not in blood) and can thus conclude that the absence of promoter methylation is not due to complete absence of methylation in our samples. Presence of methylation at sites that we did not analyze, however, cannot be excluded.

If $S D H A F 2$ or $S D H D$ would function as tumor suppressor genes in these tumors, one would expect a second mechanism of gene inactivation in addition to $\mathrm{LOH}$ in accordance with Knudsons two-hit model $[40,41]$. Absence of mutations and promoter methylation may be in agreement with the putative maternal imprinting of $S D H A F 2$ and $S D H D$ [42], but may also be suggestive of other or additional important target genes on chromosome 11q. Therefore, despite the lack of both somatic mutations and methylation in $S D H A F 2$ and $S D H D$, the significant down-regulation of both genes on the mRNA level in tumors with LOH suggested a pathogenic role of these genes in VHL-associated 
PCCs. We therefore analyzed the expression of the protein SDHB in our PCCs as it is considered a universal marker for loss of any of the SDH subunits [23]. Actually, weak SDHB staining has been reported in VHL-associated PCCs [43]. Weak SDHB immunostaining of tumor tissue could be confirmed in the majority of the tumors investigated. However, we did not find any correlation between the mRNA levels of SDHAF2 and SDHD and the expression of SDHB, making it less likely that either gene plays a major role in the development of these tumors even though the number of tumors investigated with IHC was very limited in this study.

In summary, we show a high frequency of allelic imbalance indicating LOH of both SDHAF2 and SDHD in VHL-associated PCCs that was associated with a significantly decreased expression of both genes on the mRNA level. Intensity of SDHB IHC staining, however, correlated with neither LOH nor altered mRNA levels. This and the absence of both mutations and/or methylation indicates that the studied genes $S D H A F 2$ and $S D H D$ are less likely to contribute a key genetic event for mitochondrial complex II change and subsequent formation of PCCs in carriers of $V H L$ germline mutation. Other key genetic events on 11q remain to be looked for.

\section{Declaration of interest}

The authors declare that there is no conflict of interest that could prejudice the impartiality of this scientific work.

\section{Funding}

This work was supported by grants from the Linköping University to Oliver Gimm and from the Guido Berlucchi Foundation to Giuseppe Opocher.

\section{Acknowledgements}

We thank Ms. Annette Molbaek and Ms. Åsa Schippert for valuable technical support. 


\section{References}

1. Karagiannis A, Mikhailidis DP, Athyros VG, et al (2007) Pheochromocytoma: an update on genetics and management. Endocr Relat Cancer 14:935-56.

2. Gimenez-Roqueplo AP, Burnichon N, Amar L, et al (2008) Recent advances in the genetics of phaeochromocytoma and functional paraganglioma. Clin Exp Pharmacol Physiol 35:376-9.

3. Neumann HP, Bausch B, McWhinney SR, et al (2002) Germ-line mutations in nonsyndromic pheochromocytoma. N Engl J Med 346:1459-66.

4. Welander J, Soderkvist P, and Gimm O (2011) Genetics and clinical characteristics of hereditary pheochromocytomas and paragangliomas. Endocr Relat Cancer 18:R253-76.

5. Woodward ER and Maher ER (2006) Von Hippel-Lindau disease and endocrine tumour susceptibility. Endocr Relat Cancer 13:415-25.

6. Raue F and Frank-Raue K (2010) Update multiple endocrine neoplasia type 2. Fam Cancer 9:449-57.

7. Bausch B, Borozdin W, and Neumann HP (2006) Clinical and genetic characteristics of patients with neurofibromatosis type 1 and pheochromocytoma. N Engl J Med 354:2729-31.

8. Neumann HP, Pawlu C, Peczkowska M, et al (2004) Distinct clinical features of paraganglioma syndromes associated with SDHB and SDHD gene mutations. JAMA 292:94351 .

9. Schiavi F, Boedeker CC, Bausch B, et al (2005) Predictors and prevalence of paraganglioma syndrome associated with mutations of the SDHC gene. JAMA 294:2057-63.

10. Benn DE, Gimenez-Roqueplo AP, Reilly JR, et al (2006) Clinical presentation and penetrance of pheochromocytoma/paraganglioma syndromes. J Clin Endocrinol Metab 91:827-36.

11. Peczkowska M, Cascon A, Prejbisz A, et al (2008) Extra-adrenal and adrenal pheochromocytomas associated with a germline SDHC mutation. Nat Clin Pract Endocrinol Metab 4:111-5.

12. Schlisio S, Kenchappa RS, Vredeveld LC, et al (2008) The kinesin KIF1Bbeta acts downstream from EgIN3 to induce apoptosis and is a potential 1p36 tumor suppressor. Genes Dev 22:884-93.

13. Yeh IT, Lenci RE, Qin Y, et al (2008) A germline mutation of the KIF1B beta gene on 1p36 in a family with neural and nonneural tumors. Human genetics 124:279-85.

14. Lorenzo FR, Yang C, Ng Tang Fui M, et al (2013) A novel EPAS1/HIF2A germline mutation in a congenital polycythemia with paraganglioma. J Mol Med (Berl) 91:507-12.

15. Ladroue C, Carcenac R, Leporrier M, et al (2008) PHD2 mutation and congenital erythrocytosis with paraganglioma. N Engl J Med 359:2685-92.

16. Qin Y, Yao L, King EE, et al (2010) Germline mutations in TMEM127 confer susceptibility to pheochromocytoma. Nat Genet 42:229-33.

17. Comino-Mendez I, Gracia-Aznarez FJ, Schiavi F, et al (2011) Exome sequencing identifies MAX mutations as a cause of hereditary pheochromocytoma. Nat Genet 43:663-7.

18. Chen F, Kishida T, Yao M, et al (1995) Germline mutations in the von Hippel-Lindau disease tumor suppressor gene: correlations with phenotype. Hum Mutat 5:66-75.

19. Lui WO, Chen J, Glasker S, et al (2002) Selective loss of chromosome 11 in pheochromocytomas associated with the VHL syndrome. Oncogene 21:1117-22.

20. Galan SR and Kann PH (2013) Genetics and molecular pathogenesis of pheochromocytoma and paraganglioma. Clinical endocrinology 78:165-75.

21. Hao HX, Khalimonchuk O, Schraders M, et al (2009) SDH5, a gene required for flavination of succinate dehydrogenase, is mutated in paraganglioma. Science 325:1139-42.

22. Bayley JP, Kunst HPM, Cascon A, et al (2010) SDHAF2 mutations in familial and sporadic paraganglioma and phaeochromocytoma. Lancet Oncol 11:366-372.

23. van Nederveen FH, Gaal J, Favier J, et al (2009) An immunohistochemical procedure to detect patients with paraganglioma and phaeochromocytoma with germline SDHB, SDHC, or SDHD gene mutations: a retrospective and prospective analysis. Lancet Oncol 10:764-71.

24. Cawkwell L, Bell SM, Lewis FA, et al (1993) Rapid Detection of Allele Loss in Colorectal Tumors Using Microsatellites and Fluorescent DNA Technology. Brit J Cancer 67:1262-1267. 
25. Herman JG, Graff JR, Myohanen S, et al (1996) Methylation-specific PCR: a novel PCR assay for methylation status of CpG islands. Proc Natl Acad Sci U S A 93:9821-6.

26. Welander J, Larsson C, Backdahl M, et al (2012) Integrative genomics reveals frequent somatic NF1 mutations in sporadic pheochromocytomas. Hum Mol Genet 21:5406-16.

27. Margetts CD, Astuti D, Gentle DC, et al (2005) Epigenetic analysis of HIC1, CASP8, FLIP, TSP1, DCR1, DCR2, DR4, DR5, KvDMR1, H19 and preferential 11p15.5 maternal-allele loss in von Hippel-Lindau and sporadic phaeochromocytomas. Endocr Relat Cancer 12:16172 .

28. Dong SM, Kim HS, Rha SH, et al (2001) Promoter hypermethylation of multiple genes in carcinoma of the uterine cervix. Clin Cancer Res 7:1982-6.

29. de Kok JB, Roelofs RW, Giesendorf BA, et al (2005) Normalization of gene expression measurements in tumor tissues: comparison of 13 endogenous control genes. Lab Invest 85:154-9.

30. Schmittgen TD and Livak KJ (2008) Analyzing real-time PCR data by the comparative C(T) method. Nat Protoc 3:1101-8.

31. Korpershoek E, Stobbe CK, van Nederveen FH, et al Intra-tumoral molecular heterogeneity in benign and malignant pheochromocytomas and extra-adrenal sympathetic paragangliomas. Endocr Relat Cancer 17:653-62.

32. Yao L, Barontini M, Niederle B, et al (2010) Mutations of the metabolic genes IDH1, IDH2, and SDHAF2 are not major determinants of the pseudohypoxic phenotype of sporadic pheochromocytomas and paragangliomas. J Clin Endocrinol Metab 95:1469-72.

33. Baysal BE, Ferrell RE, Willett-Brozick JE, et al (2000) Mutations in SDHD, a mitochondrial complex II gene, in hereditary paraganglioma. Science 287:848-851.

34. Astuti D, Latif F, Dallol A, et al (2001) Gene mutations in the succinate dehydrogenase subunit SDHB cause susceptibility to familial pheochromocytoma and to familial paraganglioma. Am J Hum Genet 69:49-54.

35. Niemann S and Muller U (2000) Mutations in SDHC cause autosomal dominant paraganglioma, type 3. Nat Genet 26:268-70.

36. Burnichon N, Briere JJ, Libe R, et al (2010) SDHA is a tumor suppressor gene causing paraganglioma. Hum Mol Genet 19:3011-3020.

37. Astuti D, Douglas F, Lennard TW, et al (2001) Germline SDHD mutation in familial phaeochromocytoma. Lancet 357:1181-2.

38. Gimm O, Armanios M, Dziema H, et al (2000) Somatic and occult germ-line mutations in SDHD, a mitochondrial complex II gene, in nonfamilial pheochromocytoma. Cancer Res 60:6822-5.

39. Korpershoek E, Favier J, Gaal J, et al (2011) SDHA immunohistochemistry detects germline SDHA gene mutations in apparently sporadic paragangliomas and pheochromocytomas. J Clin Endocrinol Metab 96:E1472-6.

40. Knudson AG, Jr. (1971) Mutation and cancer: statistical study of retinoblastoma. Proc Natl Acad Sci U S A 68:820-3.

41. Knudson AG (1996) Hereditary cancer: two hits revisited. J Cancer Res Clin Oncol 122:13540 .

42. Kunst HP, Rutten MH, de Monnink JP, et al (2011) SDHAF2 (PGL2-SDH5) and hereditary head and neck paraganglioma. Clin Cancer Res 17:247-54.

43. Gill AJ, Benn DE, Chou A, et al (2010) Immunohistochemistry for SDHB triages genetic testing of SDHB, SDHC, and SDHD in paraganglioma-pheochromocytoma syndromes. Hum Pathol 41:805-14. 


\begin{tabular}{|c|c|c|c|c|c|}
\hline \multicolumn{6}{|c|}{ Markers flanking the $S D H A F 2$ locus } \\
\hline $\begin{array}{l}\text { Marker } \\
\text { Name }\end{array}$ & $\begin{array}{l}\text { Position } \\
\text { Ensembl } \\
{[\mathrm{Mb}]}\end{array}$ & $\begin{array}{l}\text { Hetero- } \\
\text { zygosity }\end{array}$ & $\begin{array}{l}\text { Forward and reverse primer sequences } \\
{\left[5^{\prime} \text { to } 3^{\prime}\right]}\end{array}$ & $\begin{array}{l}\text { Annealing } \\
\text { temp. }\end{array}$ & $\begin{array}{l}\text { Product } \\
\text { size }[\mathrm{bp}]\end{array}$ \\
\hline D11S4191 & 60.00 & 0.87 & $\begin{array}{l}\text { F: 6-FAM-GCAAGATGGCCAATTAGAAG } \\
\text { R: CCTTAGTTATTTTGGTTGGAATGT }\end{array}$ & $55^{\circ} \mathrm{C}$ & $118-142$ \\
\hline D11S1765 & 60.78 & 0.79 & $\begin{array}{l}\text { F: 6-FAM-CAGAAATGCCACCCAGAGAG } \\
\text { R: TTCCGGAGTTTGCACAATCT }\end{array}$ & $57^{\circ} \mathrm{C}$ & $234-252$ \\
\hline D11S4076 & 61.36 & 0.77 & $\begin{array}{l}\text { F: 6-FAM-CATGAATGCTCTTGTCCC } \\
\text { R: AACCCCCTGGAAAATAGACT }\end{array}$ & $55^{\circ} \mathrm{C}$ & $151-163$ \\
\hline D11S1883 & 63.37 & 0.73 & $\begin{array}{l}\text { F: 6-FAM-GTGGCTCACGCCTGTAATC } \\
\text { R: TCTTTCTGTTGGTTTCGGATCT }\end{array}$ & $59{ }^{\circ} \mathrm{C}$ & $177-219$ \\
\hline \multicolumn{6}{|c|}{ Markers flanking the $S D H D$ locus } \\
\hline D11S897 & 105.74 & 0.66 & $\begin{array}{l}\text { F: 6-FAM-ATATCACAGAGGAGTCCCCT } \\
\text { R: AACTTGAAGAGCAGAAAGGG }\end{array}$ & $55^{\circ} \mathrm{C}$ & $98-118$ \\
\hline D11S1793 & 109.86 & 0.68 & $\begin{array}{l}\text { F: 6-FAM-AGTCATGCATCCTCCCTGTA } \\
\text { R: ATCCTGAACACATTCCTCAA }\end{array}$ & $56^{\circ} \mathrm{C}$ & $100-140$ \\
\hline D11S1986 & 111.3 & 0.69 & $\begin{array}{l}\text { F: 6-FAM-CCAAGATCGGACCATTGTAC } \\
\text { R: AAGCCTAAAGGTGATGGGTC }\end{array}$ & $57^{\circ} \mathrm{C}$ & $188-248$ \\
\hline D11S3179 & 112.7 & 0.74 & $\begin{array}{l}\text { F: 6-FAM-CTTCCTACCAAAGGGGC } \\
\text { R: ATCAATCCATCAGTGGGG }\end{array}$ & $55^{\circ} \mathrm{C}$ & $179-197$ \\
\hline
\end{tabular}




\begin{tabular}{|c|c|c|c|}
\hline \multicolumn{4}{|c|}{ TABLE 2. Primers and conditions used for mutation screening } \\
\hline Exon no. & $\begin{array}{l}\text { Forward and reverse primer sequences } \\
{\left[5^{\prime} \text { to } 3^{\prime}\right]}\end{array}$ & $\begin{array}{l}\text { Annealing } \\
\text { temp. }\end{array}$ & Product size $[\mathrm{bp}]$ \\
\hline 1 & $\begin{array}{l}\text { F: CTTCCGGCTCAGCTCCTC } \\
\text { R: TATCGGGCAGACGAACTCTC }\end{array}$ & $57^{\circ} \mathrm{C}$ & $118-142$ \\
\hline 2 & $\begin{array}{l}\text { F: AAAGATGTTGTGGTTTGTTCA } \\
\text { R: CAGGAAGCTGCCCGATTTA }\end{array}$ & $55^{\circ} \mathrm{C}$ & $234-252$ \\
\hline 3 & $\begin{array}{l}\text { F: CCCAGGAGTAGGAGTCTTGGT } \\
\text { R: TCAGCCTAAACTGTCCTATTTTCA }\end{array}$ & $56^{\circ} \mathrm{C}$ & $151-163$ \\
\hline 4 & $\begin{array}{l}\text { F- CCTGAGCATTGACTGACTATGG } \\
\text { R: GGGGGAAAGTTTTCTATAGTGCT }\end{array}$ & $56^{\circ} \mathrm{C}$ & $177-219$ \\
\hline \multicolumn{4}{|c|}{ The $S D H D$ gene } \\
\hline 1 & $\begin{array}{l}\text { F: GTGCAGTAAACTGCGCCTTC } \\
\text { R: CCTTCGGGTAAACATCTGGA }\end{array}$ & $58^{\circ} \mathrm{C}$ & $98-118$ \\
\hline 2 & $\begin{array}{l}\text { F: CTTCACAGTAACCCCAGTGAAA } \\
\text { R: TTTGACAAAGTTGGACACAAGAG }\end{array}$ & $56^{\circ} \mathrm{C}$ & $100-140$ \\
\hline 3 & $\begin{array}{l}\text { F: GCATTGAGATACCCTTGTGCT } \\
\text { R: TCAACAAATTTAGGGCATTTCA }\end{array}$ & $56^{\circ} \mathrm{C}$ & $188-248$ \\
\hline 4 & $\begin{array}{l}\text { F: GGAGTGGCAAATGGAGACAT } \\
\text { R: TCCTCTCAAACCTTTTCCTCA }\end{array}$ & $58^{\circ} \mathrm{C}$ & $179-197$ \\
\hline
\end{tabular}




\section{Figure legends}

Fig. 1

$\mathrm{LOH}$ analysis of microsatellite loci flanking the SDHAF2 and SDHD gene loci in paired blood and PCC tumor samples from VHL patients. Representative examples are shown where the tumor exhibits a) + c) $\mathrm{LOH}$ (indicated by arrows), present in $51-54 \%$ of the samples, and b) + d) normal heterozygosity. Allele ratios were calculated as previously described [24]. The ratio between tumor and normal allele ratios, i.e. T1:T2/N1:N2 where $\mathrm{T} 1$ and $\mathrm{N} 1$ are the peak heights of the shorter allele in the tumor and normal sample, respectively, and T2 and N2 are the peak heights of the longer allele. In cases where the ratio was $>1$, it was converted using $1 /(\mathrm{T} 1: \mathrm{T} 2 / \mathrm{N} 1: \mathrm{N} 2)$.

\section{Fig. 2}

Methylation-specific PCR in eight representative VHL-associated PCCs. Wild-type non-converted DNA (wt), unmethylated bisulfite-converted DNA (U) and methylated bisulfate-converted DNA (M) were used as controls. For the SDHAF2 and $S D H D$ promotors, only the unmethylated sequence was amplified in the samples, thus none of the tumors showed any signs of methylation. For SDHAF2, the methylated control showed a weak band with non-methylation-specific primers, possibly because of unspecificity of primers or a small amount of unmethylated DNA in this control, however this does not interfere with the interpretation of the results. Methylation-specific PCR of the gene HICl that served as a control showed methylation in all samples.

\section{Fig. 3}

Mean relative expression of SDHAF2 and SDHD mRNAs in VHL-associated PCCs. Separate bars are shown for SDHAF2 in cases with $\mathrm{LOH}(\mathrm{n}=8)$ or normal heterozygosity $(\mathrm{n}=4)$ as well as for $S D H D$ in cases with $\mathrm{LOH}(n=7)$ or normal heterozygosity $(n=6)$. The expression was normalized against the reference genes GUSB and HPRT1. The mean expression was significantly lower in tumors with LOH 
at $S D H A F 2(\mathrm{p}=0.0052)$ or $S D H D(\mathrm{p}=0.042)$ compared to tumors with normal heterozygosity. Error bars show standard deviations.

\section{Fig. 4}

Immunohistochemical detection of SDHB expression in two representative PCCs $(\mathbf{a}+\mathbf{b})$. Both tumors (adrenal medulla; arrow) showed less intense expression than the corresponding adrenal cortex $(*)$. 
a)

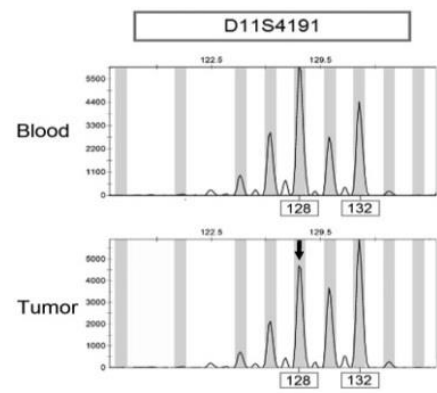

Allele ratio $=0.56$

b)
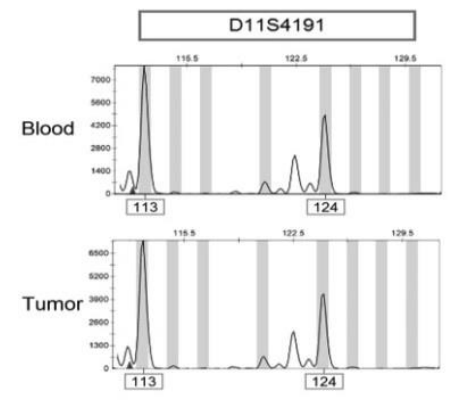

Allele ratio $=0.92$
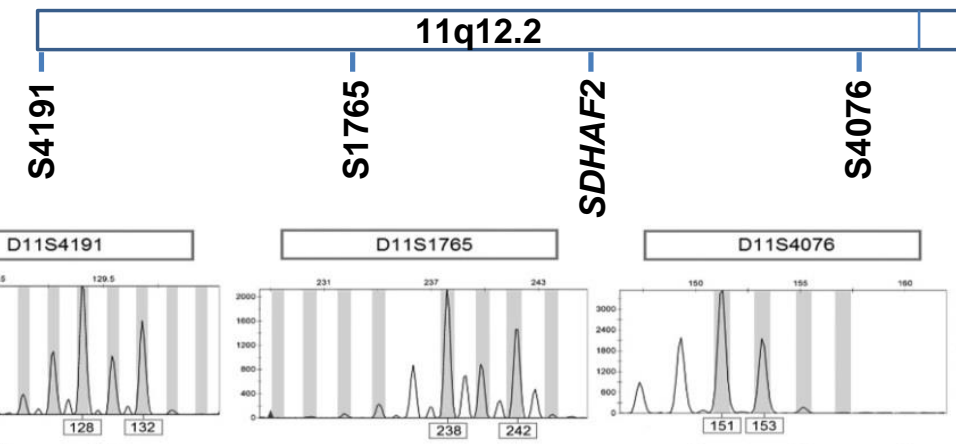

$1 5 1 \longdiv { 1 5 3 }$

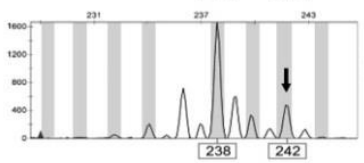

Allele ratio $=0.47$

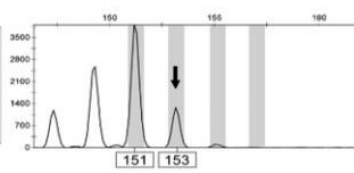

Allele ratio $=0.57$
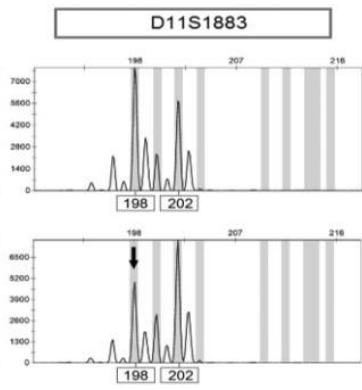

Allele ratio $=0.47$
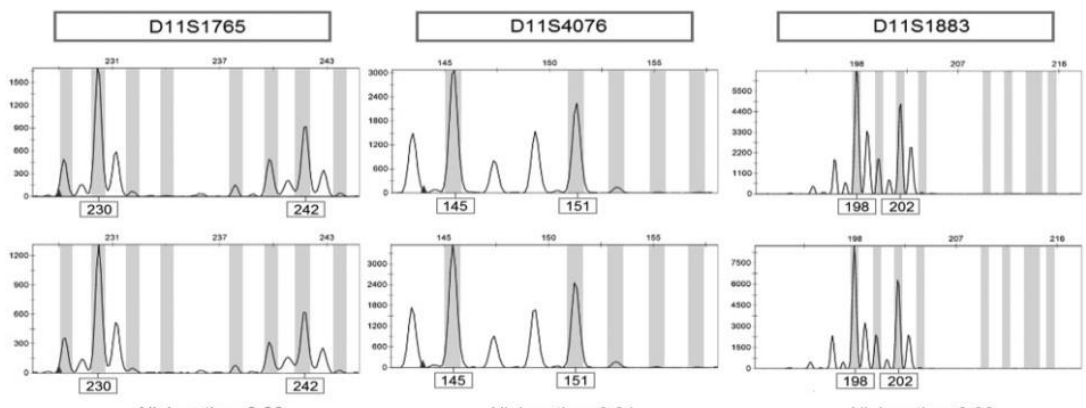

Allele ratio $=0.89$

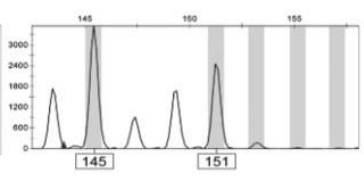

Allele ratio $=0.91$
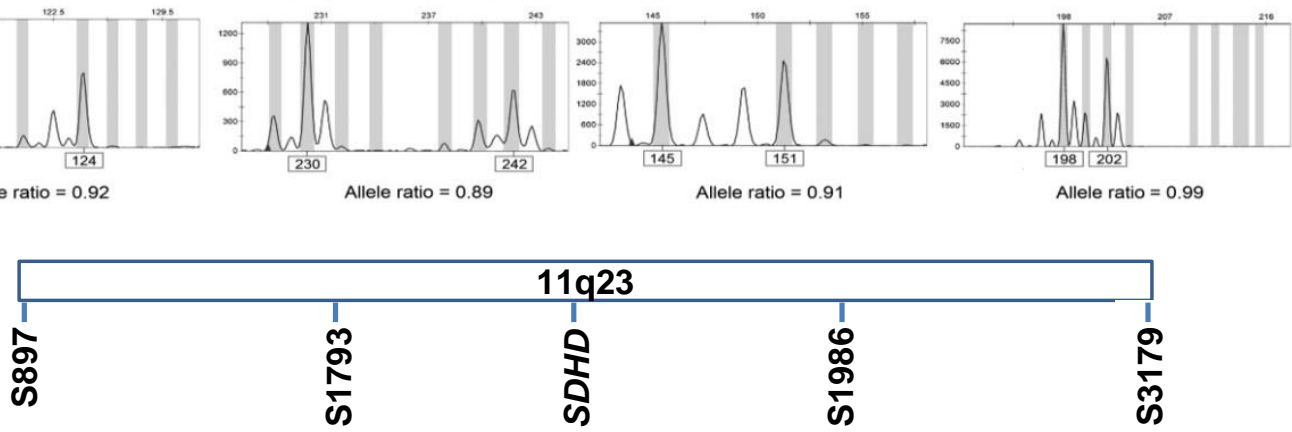

c)
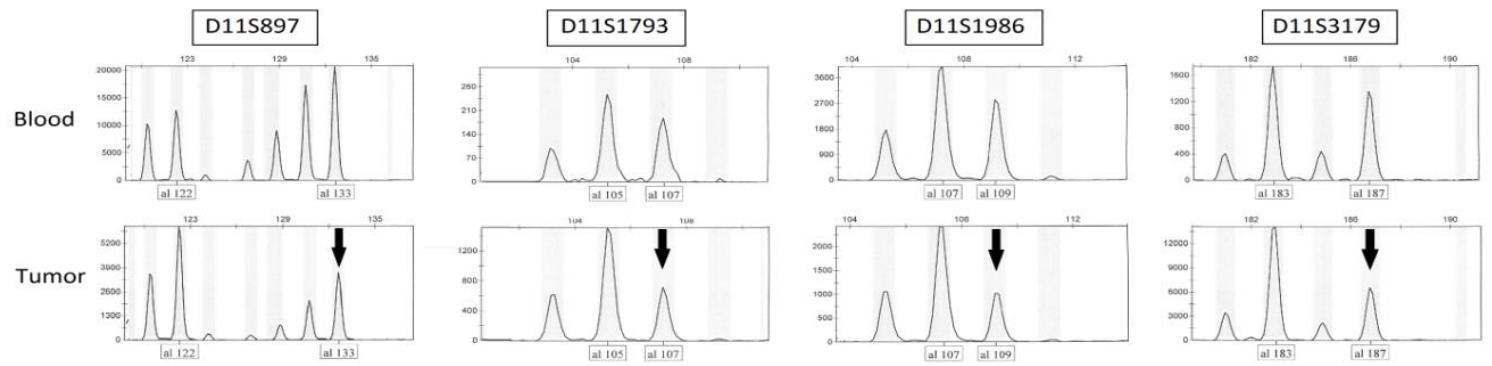

d)
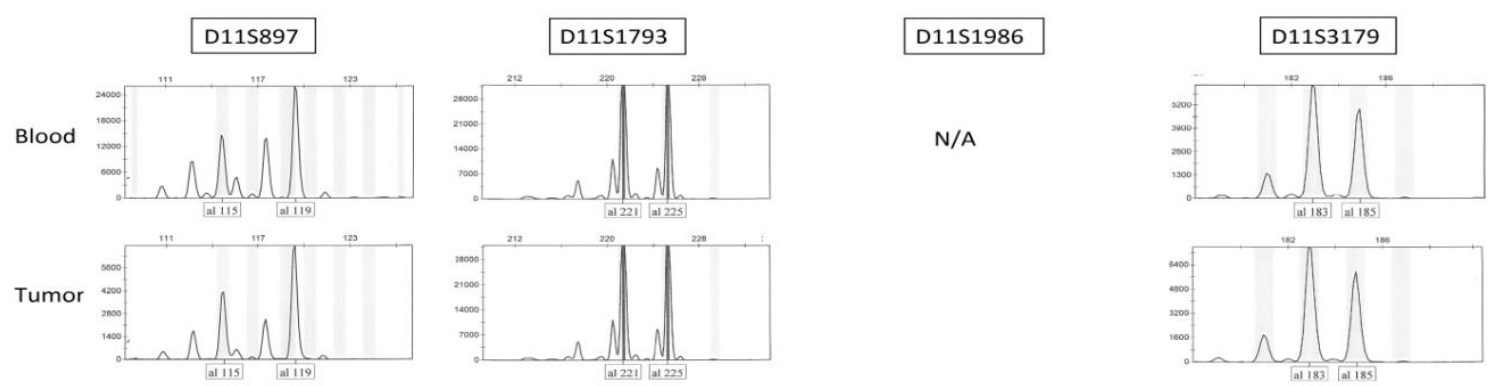
Figure 2

Methylated sequence

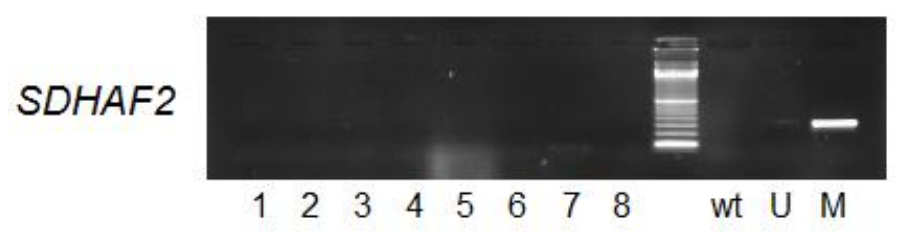

$S D H D$

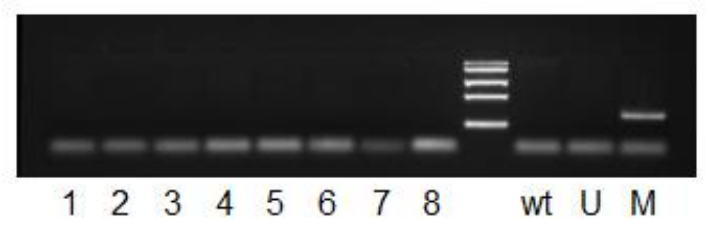

HIC1

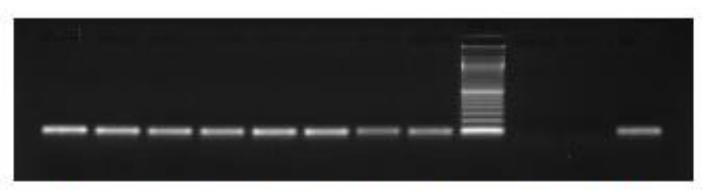

$\begin{array}{lllllllllll}1 & 2 & 3 & 4 & 5 & 6 & 7 & 8 & \text { wt } & \text { U } & \text { M }\end{array}$
Unmethylated sequence
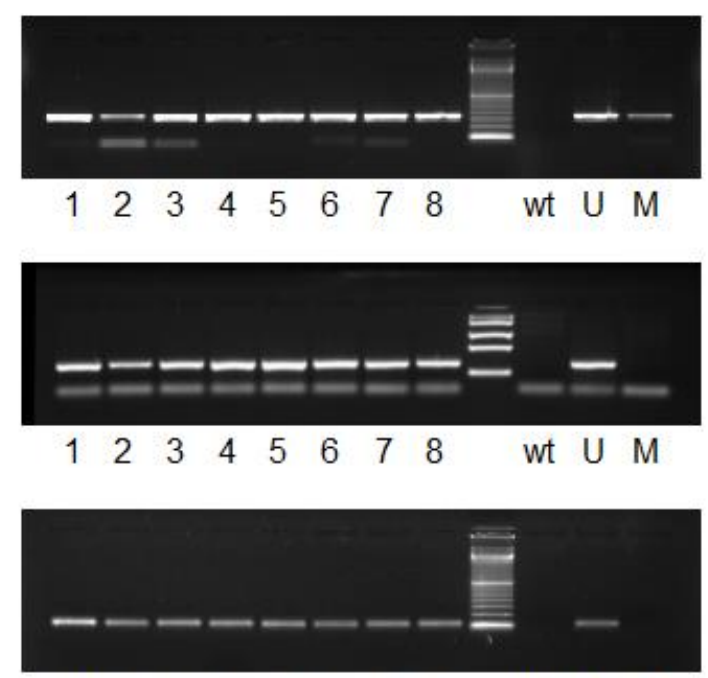

$\begin{array}{lllllllllll}1 & 2 & 3 & 4 & 5 & 6 & 7 & 8 & \text { wt } & \mathrm{U} & \mathrm{M}\end{array}$ 
Figure 3

SDHAF2

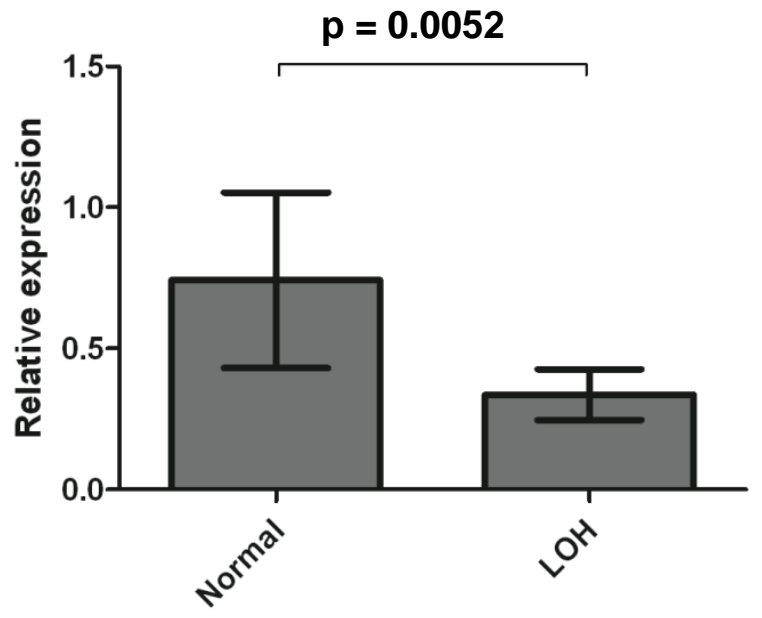

SDHD

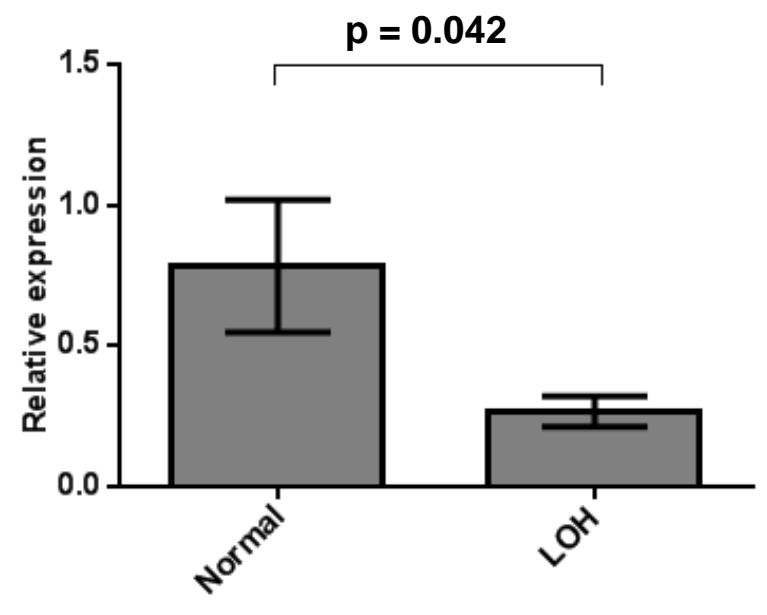


Figure 4

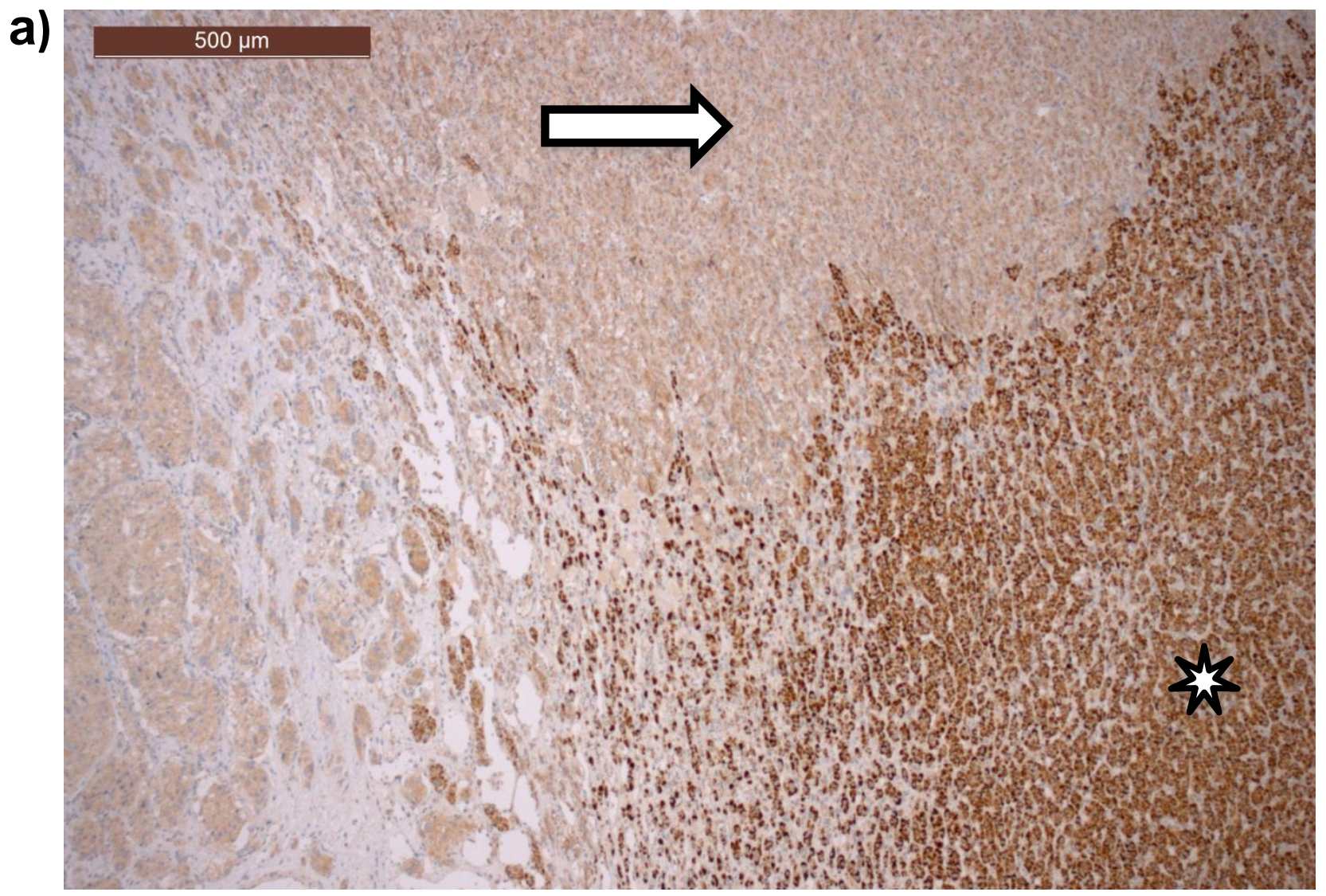

b)

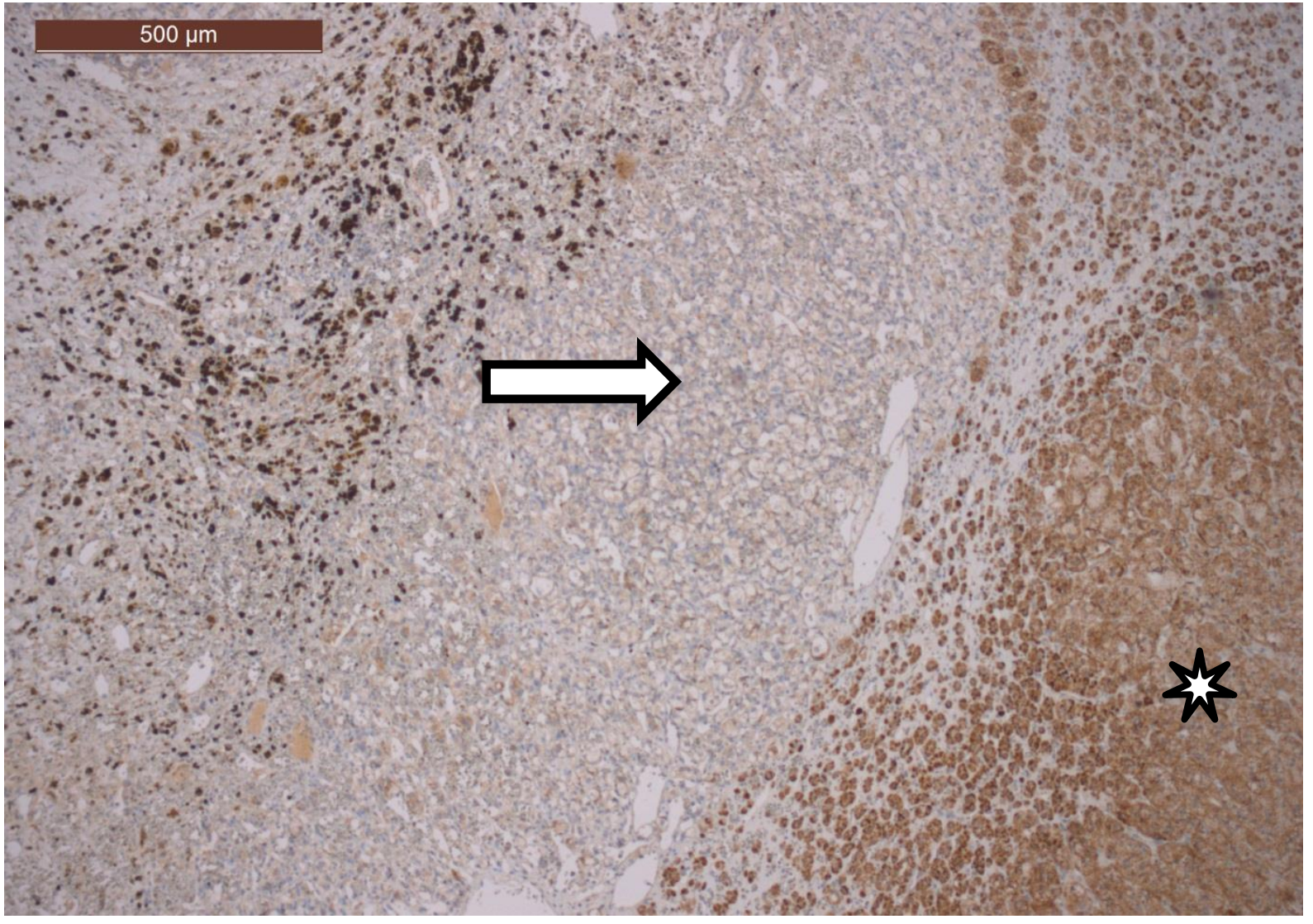

